\title{
Food safety and organic farming
}

\begin{abstract}
In 1960's the green revolution started in India with the promotion of use of high yielding varieties of seeds, extensive use of chemical fertilizers and pesticides to make India self sufficient in food grains. The green revolution aided to fight off food insecurity, but also caused environment and living beings deep affliction. 1 Thefood chain is now contaminated with chemical residues. Bioaccumulation and biomagnifications has worsened the scenario. At the same time, across the world, there is increasing consumer concern on food quality and safety. Such concerns stem the need to promote a farming system which ensures food quality and safety, such as organic farming. But, organic farming is said to be reducing the yield, again bringing back the issue of food insecurity. So, the way out of this cycle is a middle path with coordination between food processing industries and farmers
\end{abstract}

Volume 4 Issue 3 - 2017

\author{
Sonvy Gupta \\ National Institute of Food Technology Entrepreneurship and \\ Management (NIFTEM), India
}

Correspondence: Sonvy Gupta, National Institute of Food Technology Entrepreneurship and Management (NIFTEM), India, Email gupta.sonvy@gmail.com

Received: August 252016 | Published: April 26, 2017

\section{Introduction}

\section{Disadvantages of current conventional agriculture}

In India, there is a train departing from Punjab's farming district to a hospital in bordering state Rajasthan. This train is routinely filled with patients of all age groups suffering from cancer. Thus, it is named as "Cancer train". When researched it was discovered that farmers were spraying crops with abnormally high concentrations of pesticides and rarely wore protective masks. Therefore, people had high levels of pesticides in the blood. In fact, throughout the country, Indians have now been found to have high levels of pesticides in blood, skin, hair, nails, and even in the bone marrow. ${ }^{2}$ The green revolution escalated the crop production to whole new level making India one of the top producers, but the extensive farming came along with certain disadvantages. ${ }^{3}$

Use of synthetic chemicals on farm are inflicting damage to soil, underground water,air, living beings like birds, non-pest organisms and even aquatic life. $24 \%$ of greenhouse gases (GHG) (Figure 1), in India, are emitted due to fertilizers $\left(\mathrm{N}_{2} \mathrm{O}\right)$, enteric fermentation $\left(\mathrm{CH}_{4}\right)$, paddy cultivation, biomass burning and manure handling. Another major problem associated with pesticide use is that they can disperse in the environment through air and water, expanding the risk of exposure for non local organisms as well. The resistance is also increased in a pest which requires further more use of pesticides, thereby further complicating the problem and disturbing the ecological balance. ${ }^{4}$

Along with the environment the safety of the food, in terms of chemical residues, is also compromised. The food contains unwanted harmful chemical residues which are causing poisonings, birth defect, nerve damage, cancer and even deaths. ${ }^{5}$ Many synthetic pesticides also bioaccumulate. They build up in the body when the body is unable to break them down. Once they enter the body of an organism, they are permanently stored in the body tissue. In pesticides like DDT, phenomenon called biomagnifications is the observed. Such pesticides, increase in concentration with each level of the food chain.

According to AICRPPR report, 1999 - Pesticide Safety: Evaluation and Monitoring highlighted that only $2 \%$ of food commodities worldwide were found to be above MRL (maximum recommended limit), but in India this figure was as high as $20 \%$. In states like Uttar
Pradesh and Kerala, food samples exceeding MRL were as high as $46 \%$ and $53 \%$ respectively. ${ }^{6}$

\section{Impact of Organic farming on food safety}

These environmental damages and poisoning of food chain is raising consumer concerns as well. Therefore, generating need to promote organic farming. Organic farming is a sustainable method which depends upon natural way of farming and using techniques like crop rotation, vermi-composting, bio-fertilizers, crop management, animal manure, off-farm organic waste, crop residues etc., instead of synthetic chemicals, which allows soil to stay alive and food to be safe.

Organic farming enhances the food safety because of three prominent reasons:

i. lower nitrogen application (which reduce nitrate concentrations);

ii. avoidance of pesticide use (which results in virtually no pesticide residues);

iii. 3) No use of chemical fertilizers (to ensure low concentrations of chemical residues). These effects may minimize the incidence of cancer and the transfer of resistance genes from animal production systems to human pathogens. ${ }^{\text {? }}$

Positive qualities associated with organic foods include the healthy, tasty, authentic, natural, free from pesticides, antibiotics and GMO, low in nitrate content, safe and certified. Studies also suggest that organic food also has high nutritional value. According to a UK study, CLA, omega-3 fatty acids, vitamin E and carotenoids were increased in milk from organic farms with grazing dairy cows. These compounds are nutritionally desirable and have all been linked to a reduced risk of cardiovascular disease and cancer. By contrast, less desirable fatty acids (i.e. omega-6 fatty acids and CLA10) were not increased in organic milk, which helps to improve the crucial ratio between the two. ${ }^{8}$

Organic foodmarketis one of the fastest growing businesses in India with increase in demand and people are willing to pay premium due to the perceived advantage of organic food. Even the Indian government is promoting organic food in the country through National Project on 
Organic Farming(NPOF)scheme. Launched in October 2004 with an initial outlay of Rs 57 core, NPOFschemecontinues till date with substantially enhanced budget. ${ }^{9}$ India has 5.71 million ha organically certified area and produced 1.35 million MT certified organic products like oil seeds, tea, fruits, spices eta, and exports $20 \%$ to rich markets like EU and US. ${ }^{10}$

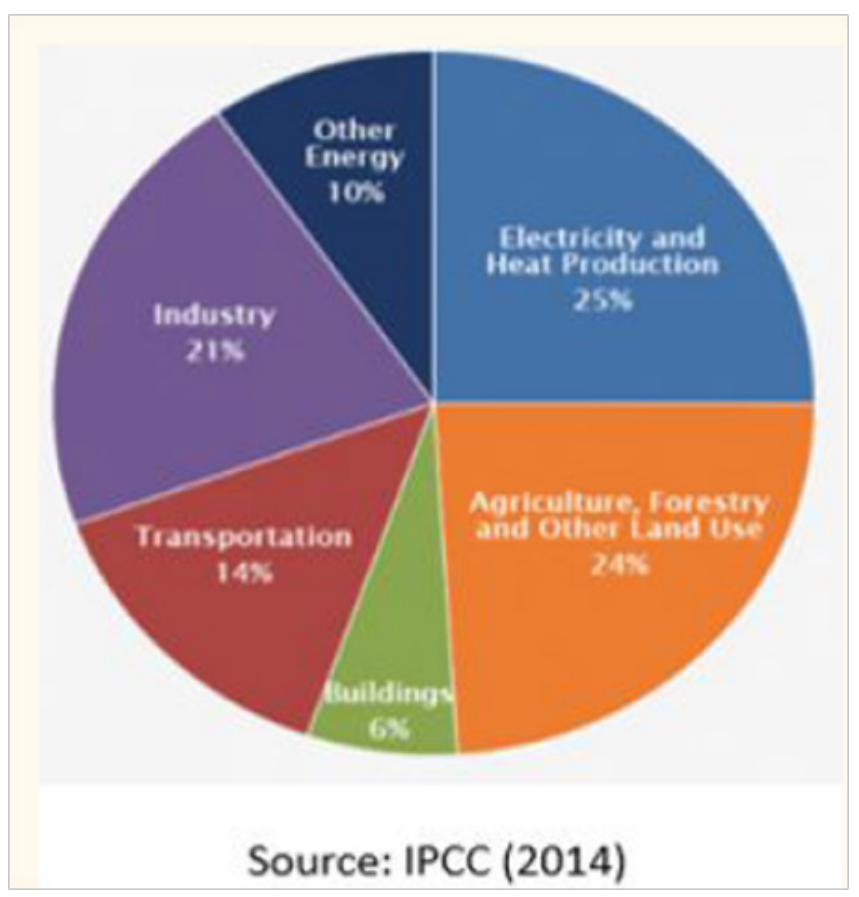

Figure I GHG emissions by economic sector in India.

The trend of organic food that was initiated in the developed regions such as Europe and North America has expanded to developing countries like India. Europe and North America are the largest consumers of organic food; however, the organic food market in Asia is likely to account for the highest growth rate over the next five years. In India, upcoming brands like 24 Organic Mantra, Organic Tattva are providing various organic foods like juices, snacks, oil, cereals etc. In 2015, sales of organic packaged food grew by $20 \%$ to reach Rs 2.4 billion and with rising consumer awareness for organic products, are expected to further rise at a CAGR of $11 \%$ at constant 2015 prices over the forecast period, reaching Rs4.0billion in 2020 (Figure 2). ${ }^{11}$

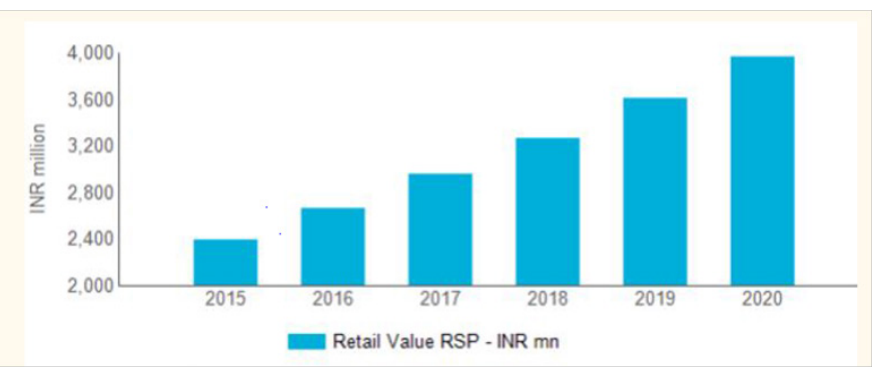

Figure 2 Market size organic packaged food-India 20I5-2020.

\section{Disadvantages of organic farming}

Researchers have raised question on the productivity of organic farming when compared to conventional farming. Few studies do state that organic farming may be able to feed all the population. ${ }^{12}$ However, according to a latest report in The Wall Street Journal, organic yields are far less than yields of conventional farming. Also, as per the 2011 survey data of National Agricultural Statistics Service, a branch of the US Department of Agriculture (USDA), organic farming would require 14.5 million acres more to equal conventional farming's production of 14 staple (human-focused food crops). ${ }^{9}$ Sikkim, India's first fully organic state, initiated to work towards it in 2003 and in 2016 achieved that goal. The graphs below indicate that overall productivity has decreased (Figure 3 ). ${ }^{13}$

The yields on organic farms have been researched as lower than conventional but the magnitude varies considerably in literature. Average yield of organic crops as a percentage of conventional crops in five European countries have been given in the Table $1 .{ }^{8}$

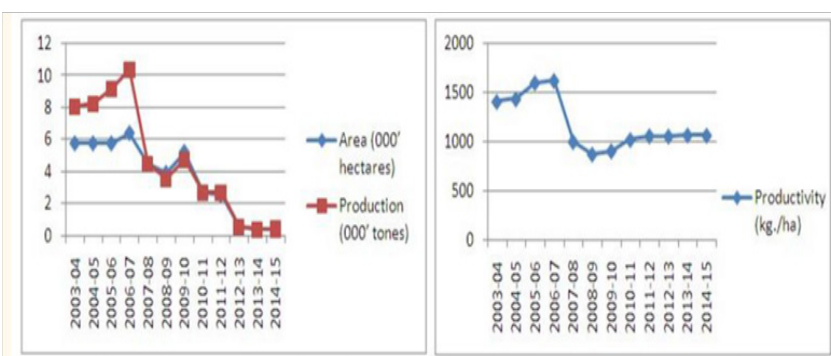

Source: Annual Reports, Food Security \& Agriculture Development Department, Government of Sikkim

Figure 3 Area, production and productivity, Sikkim, India 2003-20I5.

Table I Average yields of organic crops (as \% of conventional crops ${ }^{8}$

\begin{tabular}{llllll}
\hline & Switzer-land & Austria & Germany & Italy & France \\
\hline Wheat & $64-75$ & $62-67$ & $58-63$ & $78-98$ & $44-55$ \\
Barley & $65-84$ & $58-70$ & $62-68$ & $55-94$ & $70-80$ \\
Oats & $73-94$ & $56-75$ & & 88 & \\
Grain Maize & $85-88$ & & 70 & $55-93$ & $66-80$ \\
Oilseeds & 83 & $78-88$ & $60-67$ & $48-50$ & $67-80$ \\
Potatoes & $62-68$ & $39-54$ & $54-69$ & $62-99$ & $68-79$ \\
Pulses & 88 & $83-85$ & $49-73$ & $73-$ & 83 \\
\hline
\end{tabular}

Hence, for India, the world's second most populated country and where land is increasingly becoming scarce, adoption of only-organic route of farming could result in lower yield, thereby decreasing the food availability. ${ }^{14}$

\section{Solution}

We need a middle-path to achieve food safety and security at the same time. ${ }^{15}$ This can be achieved by using organic methods like crop rotation, crop residue management, animal manures, off-farm organic waste management, mineral grade rock additives and biological system of nutrient mobilization and plant protection, along with limited use of chemicals in amounts necessary, after soil checkup to prevent nutrient imbalance. 
This approach can reduce cost as only fraction of chemicals are being used and also will help attain the goal of security of safe food as yield is expected to increase. Environment depletion will also be reduced. Cost reduction and higher yield will also attract farmers to grow safe food in sustainable manner.

Non-persistent pesticides are less harmful to the environment because they do not build up. Though organic pesticides like neem etc. should be used, but if at all chemical pesticides are required, they should be approved non persistent pesticides, which will result in quicker breakdown of residues. Also, pesticides if present can be reduced with various food processing techniques like washing, peeling, thermal processing, baking etc. to breakdown the residues. Consequently, making food safe. ${ }^{16}$ Future prospects should include the improvisation of technology for organic farming by agricultural scientists to ensure that by purely organic farming food security can be achieved.

\section{How to progress on the middle-path?}

Farmers in India are poorly informed about their soil health, quantity of fertilizers required for healthy soil, which pesticide to use and how much. So, how will it be possible to give a practical shape to the middle-path? This can be achieved with the help of food processors.

Food processors face a continuous challenge to supply safe food. This result in increased cost of tests and analysis, a lot of rejection of batches resulting in wastage of time, money, food, energy and other resources. Therefore, if every food processing industry put these resources to better use by tracing back to farmers and making them more aware about the good agriculture practices and the middle-path, then food safety will be easier to ensure.

\section{Acknowledgements}

None.

\section{Conflict of interest}

The author declares no conflict of interest.

\section{References}

1. The Green Revolution turns to brown: Impact of Chemical Technology. Centre for education and documentation India; 2009.

2. Jangi S. Dying Fast and Slow: The pesticide poisonings in India; 2013.

3. Daniel P. The Toxic Consequences of the Green Revolution. USA; 2008.

4. Swaminathan MS. Sustainable Agriculture; Towards an Evergreen Revolution. New Delhi 10092, India: Konark Publishers PVT Ltd; 1996. 219 p.

5. Rekha, Naik SN, Prasad R. Pesticide residue in organic and conventional food-risk analysis. Journal of Chemical Health and Safety. 2006;13(6):1219.

6. Charyulu DK, Biswas S. Organic Input Production and Marketing in India-Efficiency. Issues and Policies, India: CMA Publication No-239; 2010 .

7. Hansen B, Alrøe HF, Kristensen ES, et al. Assessment of food safety in organic farming. DARCOF 52; 2002.

8. Niggli, Slabe, Anamarija, et al. Vision for an organic food and farming research agenda to $2025 ; 2008$.

9. Rakesh rao. Organic farming: A boon or a bane? Business standard; 2005.

10. National Programme for Organic Production. The Agricultural and Processed Food Products Export Development Authority (APEDA); 2017.

11. Euro monitor: Organic packaged food in India; 2016.

12. Knight M. Study: Organic yields $25 \%$ lower than conventional farming. CNN; 2012.

13. ENVIS Centre: Sikkim Status of Environment and Related Issues; 2017.

14. Ramesh P, Panwar NR, Singh AB, et al. Status of organic farming in India Current Science. 2009;98(9):1190-1194.

15. Biello D. Will Organic Food Fail to Feed the World? Scientific American; 2012.

16. Kaushik G. Food processing a tool to pesticide residue dissipation-A review. Food Research International. 2009;42(1):26-40. 